
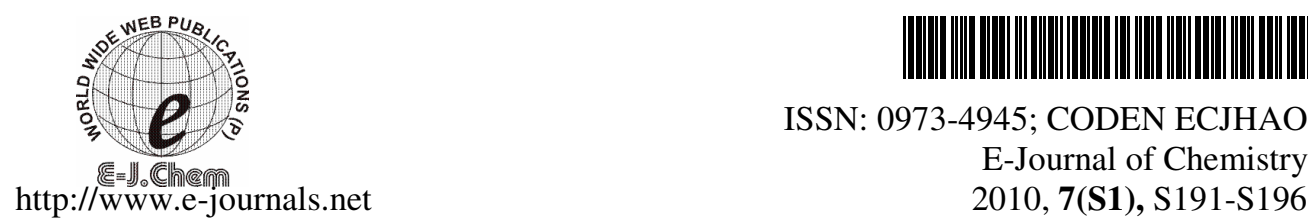

ISSN: 0973-4945; CODEN ECJHAO

E-Journal of Chemistry 2010, 7(S1), S191-S196

\title{
Synthesis and Characterization of Two Danazol Derivatives
}

\author{
LAURO FIGUEROA-VALVERDE*, FRANCISCO DÍAZ-CEDILLO ${ }^{\S}$, \\ MARIA LÓPEZ-RAMOS and ELODIA GARCIA-CERVERA
}

\author{
Facultad de Ciencias Químico-Biológicas \\ Lab. de Investigación, Universidad Autónoma de Campeche \\ Av. Agustín Melgar s/n, Col Buenavista C.P.24039 Campeche, México \\ ${ }^{\S}$ Escuela de Ciencias Biológicas del IPN. Plan de San Luís y Díaz Mirón s/n Col \\ Santo Tomas, D.F. C.P. 11340, México \\ lauro_1999@yahoo.com
}

Received 16 March 2010; Revised 25 May 2010; Accepted 20 June 2010

\begin{abstract}
Two danazol derivatives were synthesized and characterized by spectral analyses. In order to characterize the structural and chemical requirements of danazol derivatives, several parameters such as $\log P, \pi, R_{m}$ and $V_{m}$ were evaluated. The results showed an increase in the values of $\log P$ for the compound $\mathbf{6}$ in comparison with $\mathbf{3}$. The compound $\mathbf{3}$ showed an increase in the values of $\pi, R_{m}$ and $V_{m}$ with respect to 6 . These data indicate a high degree of lipophilicity and a low steric impediment for compound $\mathbf{6}$ in comparison with $\mathbf{3}$.
\end{abstract}

Keywords: Danazol derivatives, Lipophilicity, Steric impediment, Synthesis.

\section{Introduction}

The studies for the establishment of parameters relationship between biological activity of steroids and its molecular structure (QSAR), plays an important role in the development of new steroid derivatives ${ }^{1-2}$. For example the QSAR analysis of a series of steroids binding to globulin was made using the electro topological state index for each atom in the molecule ${ }^{3}$. Additionally, other studies showed a quantitative structure-activity relationship among some steroids with several parameters such as molecular volume, Van der Waals volume and including difference and square steric terms. ${ }^{4,5}$. The relationship of dihydrotestosteroneciprofloxacin conjugates with the descriptors such as $\log P, \pi, R_{m}$ and $V_{m} .{ }^{6}$ was evaluated recently. In this work our initial design included the synthesis of two danazol derivatives and its relationship with the $\log P, \pi, R_{m}$ and $V_{m}$. 


\section{Experimental}

Hemisuccinate of danazol (1) was prepared accord to the method reported by Figueroa and coworkers ${ }^{7}$. Danazol (4) and the other compounds evaluated in this study were purchased from Sigma-Aldrich Co., Ltd. The melting points of the different compounds were determined using an Electrothermal (900 model). Ultraviolet spectroscopy (UV) was carried out in dry methanol on a Perkin-Elmer model 552 spectrophotometer and infrared spectra (IR) was recorded using $\mathrm{KBr}$ pellets on a Perkin Elmer Lambda 40 spectrometer. ${ }^{1} \mathrm{H}$ and ${ }^{13} \mathrm{C}$ NMR spectra were recorded on a Varian VXR-300/5 FT NMR spectrometer at 300 and $75.4 \mathrm{MHz}$ in $\mathrm{CDCl}_{3}$ using TMS as internal standard. EIMS spectra were obtained with a Finnigan Trace GCPolaris Q. spectrometer. Elementary analysis data were acquired from a Perkin Elmer Ser. II CHNS/0 2400 elemental analyzer.

Succinic acid mono-\{6-[(2-amino-ethylamino)-methyl]-1-ethinyl-10a,12a-dimethyl2,3,3a,3b,4,5,10,10a,10b,11,12,12a-dodecahydro-1H-7-oxa-8-aza-dicyclopenta[a,h]phenanthren-1-yl\}ester (3)

$200 \mathrm{Mg}(0.46 \mathrm{mmol})$ of compound 1 was added to solution of ethylendiamine hydrochloride (2), $100 \mathrm{mg}(0.75 \mathrm{mmol})$ in $10 \mathrm{~mL}$ formaldehyde was gently refluxed for $48 \mathrm{~h}$ and then cooled to room temperature. After the solvent was removed under vacuum and the crude product was purified by crystallization from methanol:hexane:water $(3: 2: 1)$ mixture. The yield of the product was $75 \%$ and m.p $184{ }^{\circ} \mathrm{C}$.

UV (MeOH) $\lambda_{\max }:(\log \varepsilon) 210$ (2.54), $282(3.36) \mathrm{nm}$; IR $v_{\max }: 3330,1680 \mathrm{~cm}^{-1} ;{ }^{1} \mathrm{H}$ NMR $\left(300 \mathrm{MHz}, \mathrm{CDCl}_{3}\right) \delta_{\mathrm{H}}: 0.84(\mathrm{~m}, 1 \mathrm{H}), 0.92(\mathrm{~m}, 1 \mathrm{H}), 0.96(\mathrm{~s}, 3 \mathrm{H}), 1.01(\mathrm{~s}, 3 \mathrm{H}), 1.53-1.70(\mathrm{~m}$, $4 \mathrm{H}), 1.71-1.82(\mathrm{~m}, 4 \mathrm{H}), 1.87-1.89(\mathrm{~m}, 2 \mathrm{H}), 1.95-2.03(\mathrm{~m}, 3 \mathrm{H}), 2.30-2.34(\mathrm{~m}, 2 \mathrm{H}), 2.57(\mathrm{~m}$, 2H), $2.67(\mathrm{~m}, 2 \mathrm{H}), 2.74-2.80(\mathrm{~m}, 4 \mathrm{H}), 2.96(\mathrm{~s}, 1 \mathrm{H}), 3.79$ (broad, $4 \mathrm{H}), 3.98(\mathrm{~s}, 2 \mathrm{H}), 8.03(\mathrm{~s}$, $1 \mathrm{H}) \mathrm{ppm} .{ }^{13} \mathrm{C} \mathrm{NMR}\left(75.4 \mathrm{MHz}, \mathrm{CDCl}_{3}\right) \delta_{\mathrm{C}} ; 14.00(\mathrm{C}-22), 19.81(\mathrm{C}-21), 20.83$ (C-19), 22.00 (C-17), 22.90 (C-13), 29.45 (C-34), 30.60 (C-33), 30.98 (C-18), 32.17 (C-20), 33.93 (C-12), 36.60 (C-8), 41.17 (C-31), 41.42 (C-6), 46.19 (C-28), 46.40 (C-10), 51.91 (C-30), 53.10 (C9), 56.60 (C-7), 75.44 (C-27), 84.00 (C-11), 84.70 (C-26), 107.34 (C-4), 120.30 (C-15), 145.00 (C-16), 148.66 (C-3), 162.02 (C-14), 168.40 (C-40), 173.60 (C-35) ppm. MS (70 $\mathrm{eV}): \mathrm{m} / z=509.20\left([\mathrm{M}+10]^{+}\right), 432.20,285.13,215.28$. Anal. Calcd. to $\mathrm{C}_{29} \mathrm{H}_{39} \mathrm{~N}_{3} \mathrm{O}_{5}: \mathrm{C}$, $68.34 ; \mathrm{H}, 7.71 ; \mathrm{N}, 8.25$, O, 15.70. Found. C, 68.30; H, 7.67; N, 8.19.

\section{6-[(1-Ethynyl-1-hydroxy-10a,12a-dimethyl-2,3,3a,3b,4,5,10,10a,11,12,12a,dodeca-hy-} dro-1H-7-oxa-8-aza-dicyclopenta[a,h]phenanthren-6-yl-methyl)-amino]hexanoic acid (6)

A solution of compound $4(200 \mathrm{mg}, 0.59 \mathrm{mmol})$ and 6-aminohexanoic acid (5) $(155 \mathrm{mg}$, $1.18 \mathrm{mmol}$ ) in $10 \mathrm{~mL}$ of formaldehyde was gently refluxed for $48 \mathrm{~h}$ and then cooled to room temperature. After the solvent was removed under vacuum and the crude product was purified by crystallization from methanol:hexane:water $(3: 2: 1)$ mixture. The product yield was $65 \%$ and m.p $168-170{ }^{\circ} \mathrm{C}$.

UV (MeOH) $\lambda_{\max }:(\log \varepsilon) 208(1.96), 284(1.61) \mathrm{nm} ; \mathrm{IR} v_{\max } 3300,1730 \mathrm{~cm}^{-1} ;{ }^{1} \mathrm{H}$ NMR $\left(300 \mathrm{MHz}, \mathrm{CDCl}_{3}\right) \delta_{\mathrm{H}}: 0.78(\mathrm{~s}, 3 \mathrm{H}), 0.79-0.82(\mathrm{~m}, 2 \mathrm{H}), 1.01(\mathrm{~s}, 3 \mathrm{H}), 1.22(\mathrm{~d}, 2 \mathrm{H}), 1.29(\mathrm{~m}$, $1 \mathrm{H}), 1.40-161(\mathrm{~m}, 7 \mathrm{H}), 1.71-181(\mathrm{~m}, 6 \mathrm{H}), 1.94-2.02(\mathrm{~m}, 3 \mathrm{H}), 2.03(\mathrm{~m}, 1 \mathrm{H}), 2.34(\mathrm{~m}, 1 \mathrm{H})$, 2.40-2.43 (d, 2H), $3.08(\mathrm{~s}, 1 \mathrm{H}), 3.76(\mathrm{~s}, 2 \mathrm{H}), 5.60$ (broad, $3 \mathrm{H}), 8.03(1 \mathrm{H}) \mathrm{ppm} .{ }^{13} \mathrm{C}$ NMR $\left(75.4 \mathrm{MHz}, \mathrm{CDCl}_{3}\right) \delta_{\mathrm{C}} ; 14.04(\mathrm{C}-22), 19.10$ (C-21), 20.97 (C-19), 22.54 (C-17), 22.94 (C-13), 25.30 (C-30), 25.48 (C-31), 28.95 (C-29), 30.98 (C-18), 31.75 (C-20), 33.57 (C-32), 33.93 (C-5), 37.00 (C-8), 37.10 (C-12), 38.00 (C-6), 46.28 (C-26), 46.70 (C-10), 48.60 (C-28), 
52.88 (C-9), 54.41 (C-7), 75.14 (C-25), 85.85 (C-11), 90.03 (C-24), 109.84 (C-1), 116.84 (C-15), 141.96 (C-16), 148.16 (C-3), 159.79 (C-14), 175.30 (C-33) ppm; MS (70 eV): $\mathrm{m} / \mathrm{z}=$ $480.60\left([\mathrm{M}+18]^{+}\right), 3.19 .44,275.28$. Anal. Calcd. to $\mathrm{C}_{29} \mathrm{H}_{40} \mathrm{~N}_{2} \mathrm{O}_{4}: \mathrm{C}, 72.47 ; \mathrm{H}, 8.39 ; \mathrm{N}, 5.83$, O, 13.32. Found. C, 72.38; H, 8.36; N, 5.80.

\section{QSAR}

ACD Log P and KOWWIN programs ${ }^{8,9}$ were used to estimate the parameters $\log P, \pi, R_{m}, V_{m}$ of the compounds studied.

\section{Results and Discussion}

It is important to mention that several steroid derivatives has been developed using the Mannich reaction. The structural chemistry of these compounds involves an activated methyl group in ring $\mathrm{A}$ and $\mathrm{B}^{10}$, or the aliphatic side chain attached to $\mathrm{C}_{17}$. Several androgen derivatives ${ }^{11}$, have been synthesized in this way. The reactivity of hydrogen atom involved in the ring A of compound $\mathbf{1}$ was studied in this work by means of Mannich reaction. The first step was achieved by reacting the compound $\mathbf{1}$ with ethylendiamine (2) and formaldehyde to form compound $\mathbf{3}$ (Figure 1). ${ }^{1} \mathrm{H}$ NMR spectrum of compound $\mathbf{3}$ showed signals at 0.84 and $0.96 \mathrm{ppm}$ corresponding to methyl group presents in the steroid nucleus. Additionally, several signals at 2.67, 2.74 and 3.98 for methylenes bound to A-ring of compound 3; at 2.57 and 2.80 $\mathrm{ppm}$ for methylenes bound to carboxyl group were found. Finally, two signals at $2.96 \mathrm{ppm}$ for the proton of alkyne group and at $8.03 \mathrm{ppm}$ corresponding to the acidic hydrogen of $\mathrm{C}(=\mathrm{O})$ $\mathrm{OH}$ were found. ${ }^{13} \mathrm{C}$ NMR spectra display chemical shifts at 14.00 and $19.81 \mathrm{ppm}$ for the carbons of methyl presents in the steroid nucleus. The chemical shift of the methylenes bound to carboxyl group is found at 29.45, 29.48 and $168.40 \mathrm{ppm}$. Other signals at 41.17-51.91 ppm for the methylenes bound to amino group were found. There are several signals (20.83-162.02 $\mathrm{ppm}$ ) corresponding to carbons involved in the steroid nucleus; at $168.40 \mathrm{ppm}$ for ester group and at $173.60 \mathrm{ppm}$ for free carboxyl group. The presence of $\mathbf{3}$ was further confirmed from mass spectrum which showed a molecular ion at $m / z$ 509.60.

The second step was achieved by the reaction of compound 4 with aminocaproic acid (5) in presence of formaldehyde to form compound 6 (Figure 2). ${ }^{1} \mathrm{H}$ NMR spectra of 6 showed chemical shifts at 0.78 and $1.01 \mathrm{ppm}$ for methyl group present in the steroid nucleus. Additionally, several signals at 1.22, 240-2.43 and $3.76 \mathrm{ppm}$ were found for methylenes involved in arm bound to steroid. Finally, other signals at $3.06 \mathrm{ppm}$ for the proton of alkyne group at $5.60 \mathrm{ppm}$ corresponding to the acidic hydrogen of $\mathrm{C}(=\mathrm{O})-\mathrm{OH}$ were found. ${ }^{13} \mathrm{C}$ NMR spectra displays chemical shifts at 14.04 and $19.10 \mathrm{ppm}$ for the carbons of methyl group presents in the steroid nucleus of compound 6. Another chemical shifts at 25.30-28.95 and 46.28-48.60 ppm for carbons of methylenes involved in arm bound to the steroid nucleus were exhibited. In addition, two signals at 75.14 and $90.03 \mathrm{ppm}$ for carbons corresponding to alkyne group were exhibited. Another chemical shifts at 175.30 for free carboxyl group. The presence of compound $\mathbf{6}$ was further confirmed from mass spectrum which showed a molecular ion at $m / z 480.60$.

In order to characterize the structural and chemical requirements of the compounds 3 and 6, the descriptors ${ }^{12}$ such as $\log P$ and $\pi$ were calculated. $\log P$ describes the logarithmic octanol-water partition coefficient; therefore, it represents the lipophilic effects of a molecule that includes the sum of the lipophilic contributions of the parent molecule and its substituents ${ }^{13}$. The difference between the substituted and unsubstituted $\log P$ values is conditioned by the $\pi$ value for a particular substituent ${ }^{14}$. In this work, the $\log P$ and $\pi$ parameters were calculated by the method reported by Leo ${ }^{15}$. The results (Table 1 and 2, see) 
showed an increase in $\log P$ and a decrease in the $\pi$ values of compound 6 with respect to 3 . These results showed that aliphatic carbons $\left(-\mathrm{CH}_{2}^{-}\right)$in compound 6 contribute to the high lipophilicity in comparison with $\mathbf{3}$.
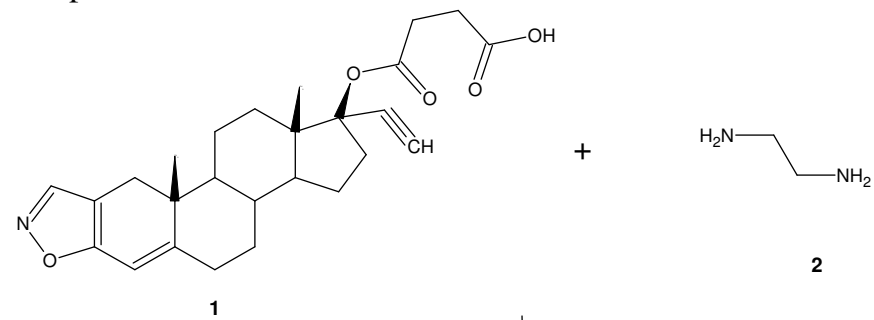

$\left.\right|_{2} \mathrm{C}=\mathrm{O}$

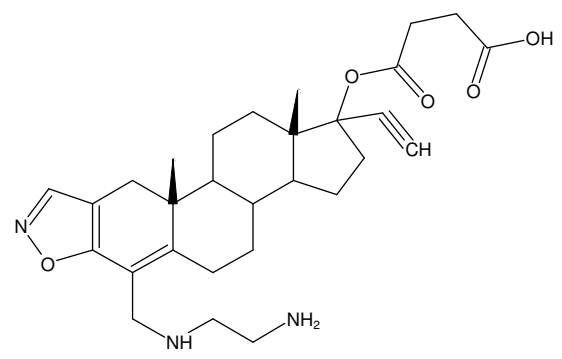

3

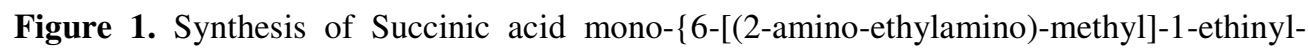
10a,12a- dimethyl-2,3, 3a, 3b,4,5,10,10a, 10b,11,12, 12a-dodecahydro-1 H-7-oxa-8-azadicyclopenta[a,h]- phenanthren-1-yl $\}$ ester (3)<smiles>C#CC1(O)CCC2C3CCC4=Cc5oncc5CC4(C)C3CCC21C</smiles>

4<smiles>NCCCCCC(=O)O</smiles>

5<smiles>C#C[C@]1(O)CCC2C3CCC4=C(CNCCCCCC(=O)O)c5oncc5C[C@]4(C)C3CCC21C</smiles>

6

Figure 2. Synthesis of 6-[(1-ethynyl-1-hydroxy-10a,12a-dimethyl-2,3,3a,3b,4,5,10, 10a,11,12,12a, dodeca-hy-dro-1H-7-oxa-8-aza-dicyclopenta[a,h]phenanthren-6-yl-methyl)amino]hexanoic acid (6). 
Table 1. Physicochemical parameters LogKow and $\pi$ of hemisuccinate of danazolethylendiamine (3)

\begin{tabular}{|c|c|c|}
\hline Compound & LogKow Fragment & Contibutions \\
\hline \multirow{19}{*}{$\begin{array}{l}\text { Hemisuccinate of danazol- } \\
\text { ethylen-diamine }\end{array}$} & -CH3 [aliphatic carbon] & 1.0946 \\
\hline & -CH2- [aliphatic carbon] & 5.8932 \\
\hline & - $\mathrm{CH}$ [aliphatic carbon] & 1.0842 \\
\hline & $=\mathrm{CH}-$ or $=\mathrm{C}<$ [olefinc carbon $]$ & 0.7672 \\
\hline & \#C [acetylenic carbon] & 0.2668 \\
\hline & -NH2 [aliphatic attach] & -1.4148 \\
\hline & -NH- [aliphatic attach] & -1.4962 \\
\hline & Aromatic Carbon & 0.8820 \\
\hline & $-\mathrm{COOH}$ [acid, aliphatic attach] & -0.6895 \\
\hline & $-\mathrm{C}(=\mathrm{O}) \mathrm{O}$ [ester, aliphatic attach] & -0.9505 \\
\hline & Aromatic Oxygen & -0.0423 \\
\hline & Aromatic Nitrogen [5-member ring] & -0.5262 \\
\hline & -tert Carbon [3 or more carbon attach] & 0.8028 \\
\hline & Fused aliphatic ring unit correction & -2.0526 \\
\hline & Oxazole ring (non-fused) correction & -0.3279 \\
\hline & Amino acid (non- $\alpha$ carbon type) cor. & -3.2000 \\
\hline & Equation Constant & 0.2290 \\
\hline & Log Kow & 0.3198 \\
\hline & $\pi$ & 3.8869 \\
\hline
\end{tabular}

Table 2. Physicochemical parameters LogKow and $\pi$ of danazol-aminocaproic acid (6)

\begin{tabular}{llc}
\hline & LogKow Fragment & Contibutions \\
\cline { 2 - 3 } & $-\mathrm{CH}$ [aliphatic carbon] & 1.0946 \\
& $-\mathrm{CH}$ - [aliphatic carbon] & 6.3843 \\
& $-\mathrm{CH}$ [aliphatic carbon] & 1.0842 \\
& $=\mathrm{CH}-\mathrm{or}=\mathrm{C}<$ [olefinc carbon] & 0.7672 \\
& [acetylenic carbon] & 0.2668 \\
& $-\mathrm{OH}$ [hydroxy, aliphatic attach] & -1.4086 \\
& $-\mathrm{NH}$ [ [aliphatic attach] & -1.4962 \\
& Aromatic Carbon & 0.8820 \\
Danazol-aminocaproic acid & $-\mathrm{COOH}$ [acid, aliphatic attach] & -0.6895 \\
& Aromatic Oxygen & -0.0423 \\
& Aromatic Nitrogen [5-member ring] & -0.5262 \\
& -tert Carbon [3 or more carbon attach] & 0.8028 \\
& Fused aliphatic ring unit correction & -2.0526 \\
& Oxazole ring (non-fused) correction & -0.3279 \\
& Amino acid (non- $\alpha$ carbon type) cor. & -3.2000 \\
& Equation Constant & 0.2290 \\
Log Kow & 1.7676 \\
$\pi$ & 2.4391 \\
\hline
\end{tabular}

On the other hand, other steric constants such as the molar volume $\left(\mathrm{V}_{\mathrm{m}}\right)$ and molar refractivity $\left(\mathrm{R}_{\mathrm{m}}\right)$ were calculated (Table 3 ). These options are a useful tool for the correlation of different properties that depend on characteristics of substituents attached to a constant reaction center. The results showed an increase in both $R_{m}$ and $V_{m}$ values for $\mathbf{3}$ in comparison 
with 6. These data indicate a high steric impediment and different conformational preferences and internal rotation of $\mathbf{3}$ in comparison with $\mathbf{6}$. These data are supported by studies of Bryantsev and coworkers ${ }^{16}$, who showed that conformational differences between several chemical functional groups have important consequences.

Table 3. Physicochemical parameters $R_{m}$ and $V_{m}$ of compounds 3 and 6

\begin{tabular}{ccc}
\hline Compound & $\mathrm{R}_{\mathrm{m}}, \mathrm{cm}^{3}$ & $\mathrm{~V}_{\mathrm{m}}, \mathrm{cm}^{3}$ \\
\hline $\mathbf{3}$ & 137.26 & 401.90 \\
$\mathbf{6}$ & 133.31 & 393.00 \\
\hline
\end{tabular}

\section{Conclusion}

The results indicate a high degree of lipophilicity and a low steric impediment of compound $\mathbf{6}$ in comparison with $\mathbf{3}$.

\section{References}

1. Mickelson K E, Forsthoefel J and Westphal U, Biochem., 1981, 20(1), 6211-6218.

2. Horman E R, Dinan L and Whiting P. J Comput Aided Mol Des., 2003, 17(2-4), 135-153.

3. De Gregorio C, Kier L B and Hall L H, J Comput Aided Mol Des., 1998, 12(6), 557-561.

4. Coburn A R and Solo J A, J Med Chem., 1976, 19(6), 748-756.

5. Coats A E, Perspect Drug Discov Design, 1998, 14, 199-213.

6. Figueroa-Valverde L, Díaz-Cedillo F, Camacho-Luis A, López-Ramos M and García-Cervera E, Monatsh Chem., 2010, 141(3), 373-380, (DOI 10.1007/s00706010-0263-y)

7. Figueroa-Valverde L, Díaz-Cedillo F, López-Ramos M and Díaz-Ku E, Asian J Chem., 2009, 21, 6209.

8. Azencott A C, Ksikes A, Swamidass J S, Chen H J, Ralaivola L and Baldi P, J Chem Inf Model., 2007, 47(3), 965-974.

9. Thompson J S, Hattotuwagama K C, Holliday D J and Flower R D, Bioinformation, 2006, 1(7), 237-241.

10. Waid H T and Taurinis A, Can J Chem., 1960, 38, 1983-1986.

11. Ceballos G, Figueroa L, Rubio I, Gallo G, Garcia A, Martinez A, Yañez R, Perez J, Morato T and Chamorro G, J Cardiov Pharm., 1999, 33(5), 691-697.

12. Leo A, Jow PY and Silipo C, J Med Chem., 1975, 18(9), 865-868.

13. Leo A and Hoekman D, Perspect Drug Discov Design, 2000, 18, 19-38.

14. Hansch C, Leo A and Taft RW, Chem Rev., 1991, 91, 165.

15. Mannhold R and Waterbeemd H. J Comput Aided Mol Design, 2001, 15, 337.

16. Bryantsev S V and Hay P B, J Phys Chem., 2006, 110, 4678. 


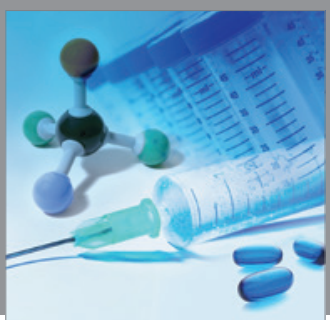

International Journal of

Medicinal Chemistry

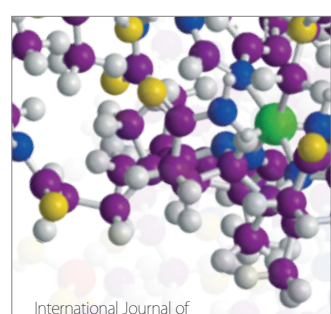

Carbohydrate Chemistry

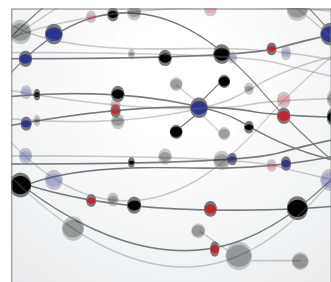

The Scientific World Journal
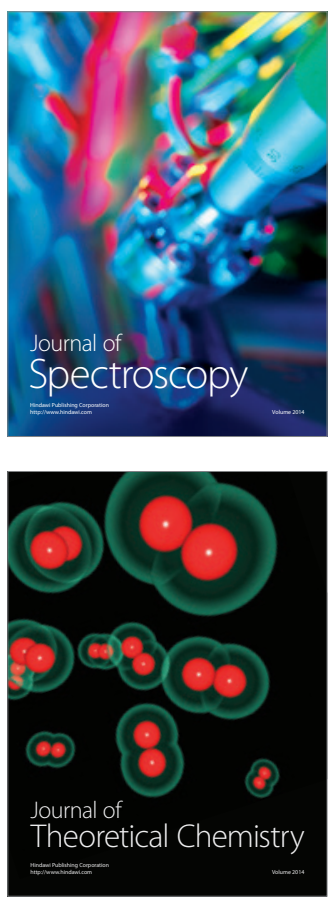
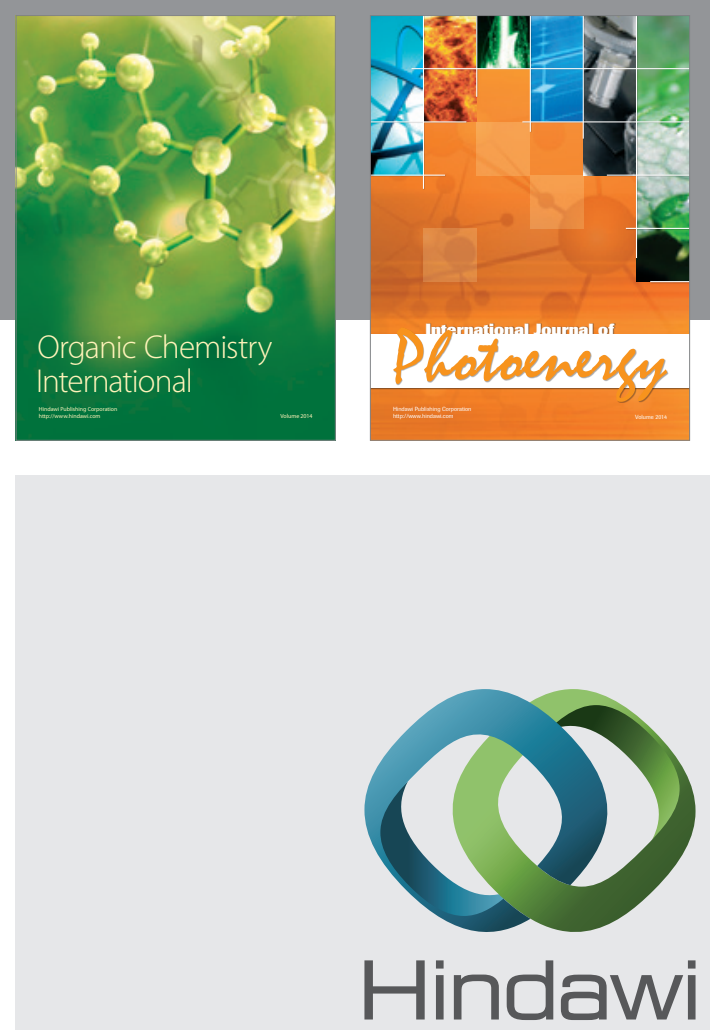

Submit your manuscripts at

http://www.hindawi.com
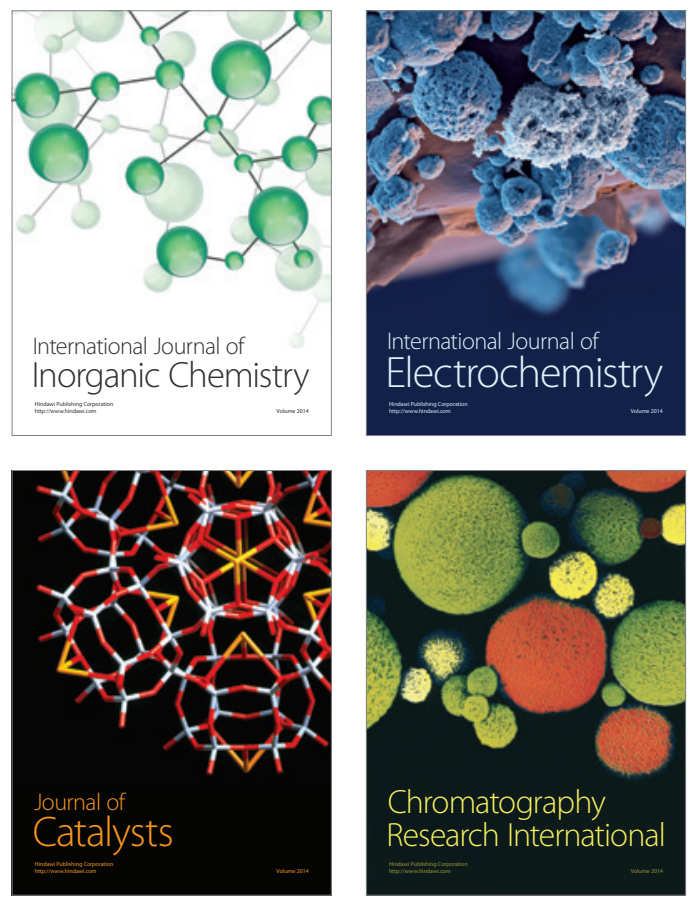
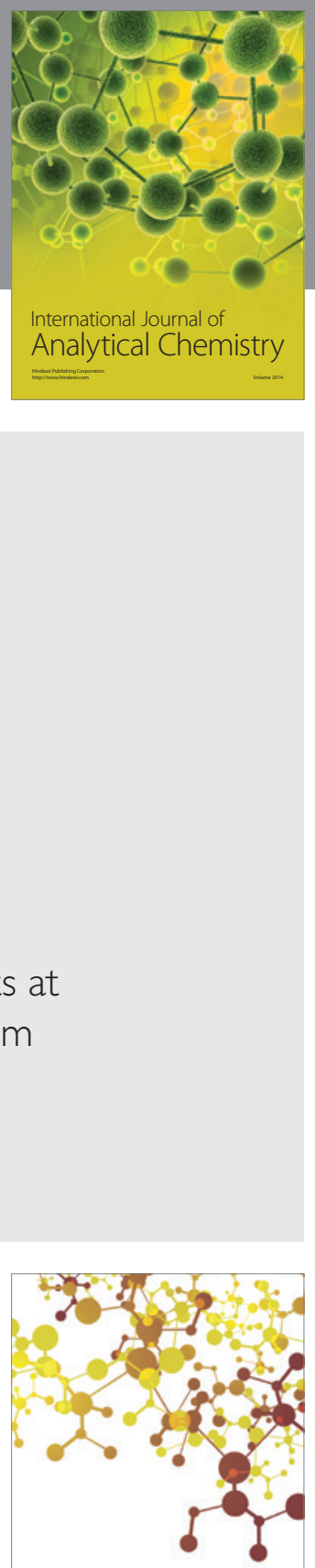

Journal of

Applied Chemistry
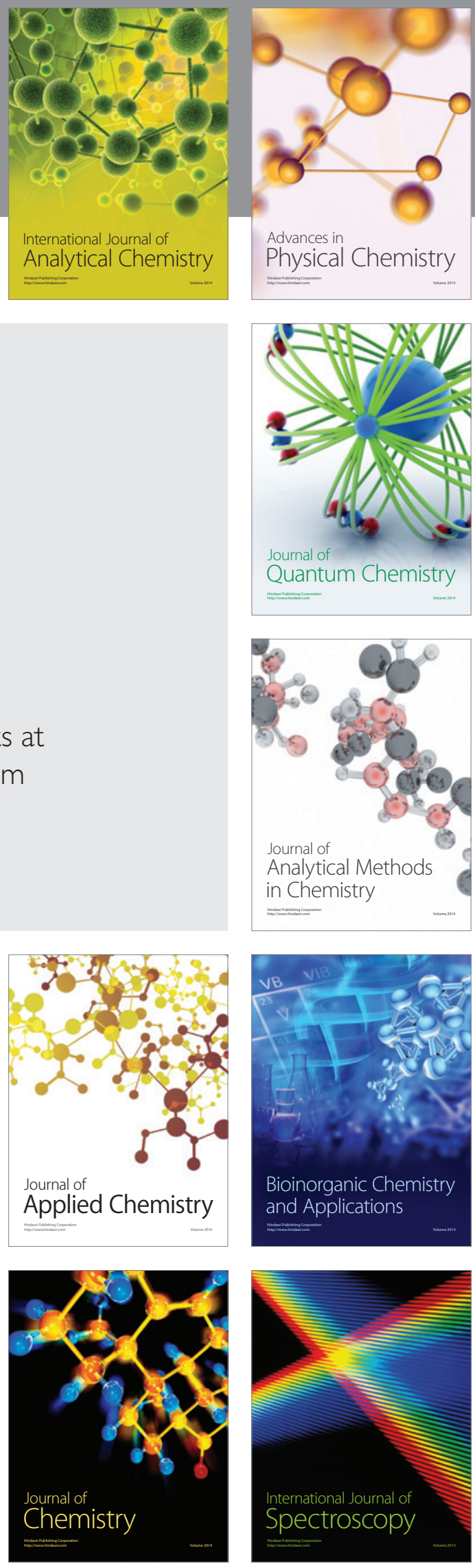